\title{
Child Development Assessment: A Guide to Nurses' (Malay Version)
}

\author{
Uqbah Iqbal* \\ Department of Social Sciences and Humanities, Malaysia
}

*Corresponding author: Uqbah Iqbal, School of History, Politics and Strategy, Faculty of Social Sciences and Humanities, UKM 43650, Bangi Selangor, Malaysia.
Received Date: August 29, 2018

Published Date: October 23, 2018

\section{Opinion}

Written by Dr. Wan Asma Wan Ismail, this handbook for nurses is published to assist nurses in identifying children who are facing a developmental problem at the earliest possible stage. The book also attempts to present practical ways that can be done at the District Hospital or Health Center if the affected family has difficulty attending the treatment at the General Hospital or University Hospital. Since Malaysia is still lacking in rehabilitation, especially the way it works, the knowledge presented in this book is useful for nurses to help the recovery program be more effective. This can also reduce the problem of waiting too late, treatment can be done in the community, saving expenses, reducing the inconvenience of the affected family, the child may be more likely to get treatment at the clinic he or she normally visits from childhood and many other benefits. The book was published following a child development assessment course held at Universiti Sains Malaysia by the National Developmental Group at the national level. This book is published to provide written guidance that can be used as a reference anytime they work. This book received contributions from almost all members of the Children's Development Group. The book aims to provide guidance to nurses in order to track problematic cases especially for repeated checks for children with high risk of developing problems. The nurse should refer to the cases found to have early symptoms to their doctors to ensure the problem.

There are some examples of situations that mothers may experience during pregnancy that can affect the development of a child, mothers who have bloodshed in the early, middle or late stage of pregnancy, mothers who suffer from infections such as Rubella germs, syphilis, HIV (AIDS) and so on, mothers who suffer from infections in the urinary tract may result in inadequate baby births, fetal movement should also be noted. Hypotonic children sometimes show less signs of movement than ever before, mothers who experience uterine contraction and pain before the end of the month should be promptly identified so that treatment can be given to prevent premature birth of breeze. A premature birth child and low weight will face many problems which can affect the development of the child. Advice should be given to mothers to give birth to a child in the hospital to ensure that the baby has optimum facilities at birth. If there is any problem during the birth, then the problem can be immediately and effective. For nurses who are directly involved in childbirth, always practice hygiene and sterility in order to prevent the baby from developing a bacterial infection that can cause septicemia or meningitis. After the birth of the baby into the world, dry the baby as soon as possible to avoid the problem of cold (hypotermia) where cold is a factor that can be avoided. If left untreated it can cause serious problems such as acidosis. Mothers who have medical problems such as high blood pressure during pregnancy or diabetes need to get early treatment.

Moral support is important given by a nurse to the mother throughout the pregnancy process especially during childbirth. Speak softly and politely and try to understand and listen to their complaints. For mothers or anyone else who is in trouble, face a person who wants to listen sincere and interested can get rid of the complaints they face. A nurse must be gentle, want to understand a mother's problem, sympathize, listen sincerely, speak politely and give useful advice. 